\title{
Considerações sobre a educação patrimonial no ensino de Geografia no Colégio Estadual Marechal Artur da Costa e Silva, Porto Nacional (TO)
}

\author{
Considerations on heritage education in Geography teaching at the State \\ School Marechal Artur da Costa e Silva, Porto Nacional Tocantins, Brazil
}

\author{
Rosane BaLSAN ${ }^{a}$ \\ Kely Barbosa DA Silva ${ }^{b}$ \\ ${ }^{a}$ Professora adjunta da Universidade Federal do Tocantins, campus de Porto Nacional. \\ E-mail: rosanebalsan@uft.edu.br

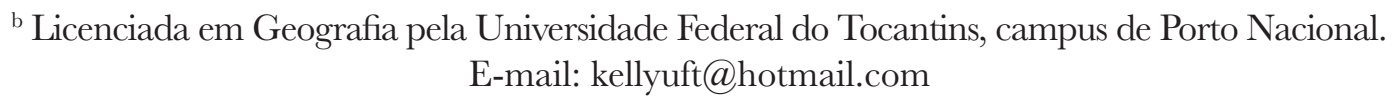

O ensino da Geografia difunde-se em um amplo conjunto de dificuldades, tanto no Ensino Fundamental quanto no Médio, culminando, muitas vezes, no fracasso do processo de ensino-aprendizagem, pois seu propósito é permitir ao aluno perceber que ele faz parte de uma realidade maior, atuando como agente transformador de seu meio e grupo social. Trata-se de um levantamento bibliográfico exploratório com abordagem quantitativa, cujo objetivo foi investigar como as professoras de Geografia do Colégio Estadual Marechal Artur da Costa e Silva, situado no município de Porto Nacional (TO), cidade tombada pelo Iphan como patrimônio histórico e cultural, vêm abordando a temática da educação patrimonial em sala de aula e na escola, quais seus anseios e dificuldades, bem como analisar o livro didático trabalhado em sala de aula quanto à abordagem das questões voltadas à educação patrimonial. Foram entrevistadas duas professoras e, a partir da análise das entrevistas, evidenciou-se que elas compreendem o conceito de cultura como todos os costumes, crenças, tradições e saberes de um determinado grupo. São desenvolvidas atividades culturais na escola, dentre elas o projeto "Café Literário", saraus realizados bimestralmente e Semana da Cultura. Desse modo, este artigo visa a estimular a reflexão sobre a educação patrimonial voltada ao ensino de Geografia, propiciando ao educando interpretar os bens culturais, tornando-os um elemento importante de promoção e vivência da cidadania participativa.

Palavras-chave: educação patrimonial, geografia, Porto Nacional, Tocantins.

The teaching of Geography diffuses a wide range of difficulties, both in elementary and high school, often culminating on the failure of the teaching-learning process, because its purpose is to allow students realize that they are part of a greater reality, acting as agents in their environment and social group. It is a bibliographical exploratory survey with a quantitative approach, which objective was to investigate how Geography teachers of the State School Marechal Artur da Costa e Silva, located in the city of Porto National (Tocantins, Brazil), listed by Iphan as a Brazilian historical and cultural heritage, addresses the theme of heritage education in the classroom and at school, what their concerns and difficulties are, as well as to analyze the textbook used in classroom and its approach to the questions focused on heritage education. Two teachers were interviewed and, from the analysis of these interviews, it became clear they understand the concept of culture as all the customs, traditions, beliefs and knowledge of a particular group. Some cultural activities are developed at school, among them the "Literary Café" project, soirées held every two months as well as a "Culture Week". Thus, this article aims to stimulate reflection on the heritage education focused on teaching Geography, allowing the learners to interpret the cultural heritage, making them an important element of promotion and experience in participatory citizenship.

Keywords: heritage education, geography, Porto Nacional, Tocantins, Brazil. 


\section{INTRODUÇÃO}

A representação do espaço pelas pessoas difunde-se em uma série de significados fundamentais para a assimilação da realidade. Nesse processo a escola possui papel singular, por ser mediadora do conhecimento e responsável pela sistematização e organização de conteúdos explicativos suscetíveis ao desenvolvimento da autonomia de pensamento e consciência libertadora entre alunos, professores e as comunidades associadas de forma direta a todos. Deve, ainda, favorecer a sustentabilidade por meio da relação harmoniosa entre a natureza e a cultura, rompendo com ideologias desfavoráveis, disseminando valores culturais e resgatando o caráter histórico e geográfico do espaço no qual estamos inseridos, promovendo ações de preservação e transmissão da importância desses valores às gerações futuras (OLIVEIRA; CARDOSO, 2011).

Segundo Oliveira e Cardoso (Ibidem), o ensino de Geografia difunde-se em um amplo conjunto de dificuldades, tanto no Ensino Fundamental quanto Médio, permeadas por profundas tensões subjacentes às mudanças e transformações cognitivas condicionadas pelo processo de desenvolvimento psicossocial, biológico e cultural dos alunos, culminando, muitas vezes, no fracasso do processo de ensino e aprendizagem.

A Geografia tem muito a contribuir para a educação patrimonial, que é uma proposta interdisciplinar de ensino voltada para questões pertinentes ao patrimônio ambiental e cultural, podendo ser aplicada em comunidades, bem como em escolas próximas a patrimônios históricos, com o objetivo de sensibilização sobre a importância do reconhecimento, da valorização e da conservação do rico patrimônio histórico e arqueológico de seus territórios, muitas vezes desconhecidos por grande parte da comunidade (PACHECO; VARGAS, 2009).

O estudo do lugar em que vivemos possibilita conhecer as riquezas históricas existentes, como é o caso de Porto Nacional, no estado de Tocantins, tombado no dia 27 de novembro de 2008 pelo Instituto do Patrimônio Histórico e Artístico Nacional. (IPHAN, 2008).

Fundado em 13 de julho de 1738 e emancipado em 13 de julho de 1861, Porto Nacional está situado a $60 \mathrm{~km}$ de Palmas e é uma das cidades do estado do Tocantins que apresenta grande potencial em valor histórico, artístico, cultural e religioso (NASCIMENTO; BALSAN, 2014). Segundo o Instituto Brasileiro de Geografia e Estatística (BRASIL, 2015), a população estimada para Porto Nacional em 2014 era de 51.846 habitantes.
A área tombada envolve aproximadamente 250 edificações e parte da zona central da cidade. Dentre as riquezas históricas tombadas, há a catedral de Nossa Senhora das Mercês, padroeira da cidade, que teve seus primeiros registros datados em 1810, tendo sido inaugurada em 1903. Na década de 1980 foi fundado o Museu Histórico e Cultural de Porto Nacional (PREFEITURA DE PORTO NAGIONAL, 2015b). O tombamento de Porto Nacional compreende o sítio natural, a malha urbana e as arquiteturas nela implantadas desde a fundação do município. Esse patrimônio ainda é pouco conhecido por sua população, bem como regiões circunvizinhas, devendo, portanto, ser objeto de intervenção por parte da escola, no intuito de conhecer e valorizar essa riqueza.

Nesse sentido, este artigo objetivou compreender como as professoras de Geografia do $6^{\circ}$ ao $9^{\circ}$ ano do Ensino Fundamental do Colégio Estadual Marechal Artur da Costa e Silva, situado na cidade de Porto Nacional, abordam a temática de educação patrimonial em sala de aula. O referido colégio iniciou suas atividades em 1968, sendo considerado uma das escolas pioneiras do município. Sua unidade escolar situa-se no bairro Jardim Querido, atendendo atualmente a 480 alunos, e funciona nos três turnos, com Ensino Fundamental do $3^{\circ}$ ao $9^{\circ}$ ano, Ensino Médio e $3^{\circ}$ segmento de Educação de Jovens e Adultos (EJA) (Idem, 2015a). Para isso, foi necessário investigar, com as professoras, as discussões concernentes às questões culturais que têm sido realizadas em sala de aula e na escola como um todo, e que entendimento apresentam a respeito dessa temática. Para tanto, foram analisados os livros didáticos de Geografia utilizados na sala de aula e aplicado um questionário às professoras, a fim de saber quais seus anseios e dificuldades para trabalhar essa temática.

Este artigo visa a investigar como as docentes de Geografia do Colégio Estadual Marechal Artur da Costa e Silva, situado no município de Porto Nacional (TO), vêm abordando a temática da educação patrimonial em sala de aula e na escola, bem como identificar quais os anseios e dificuldades encontrados para ministrar este tema, além de analisar os livros didáticos do $6^{\circ}$ ao $9^{\circ}$ ano do Ensino Fundamental utilizados pelos professores e alunos, buscando constatar se abordam questões voltadas à cultura e aos bens patrimoniais.

Partindo do exposto, este trabalho sustenta-se na abordagem qualitativa, pois estima o conhecimento e a experiência das professoras. Oliveira (2002) ressalta que: 
As pesquisas que se utilizam da abordagem qualitativa possuem facilidade de poder descrever a complexidade de uma determinada hipótese ou problema, analisar a interpretação de certas variáveis, compreender e classificar processos dinâmicos experimentados por grupos sociais, apresentar contribuições no processo de mudança, criação ou formação de opiniões de determinado grupo e permitir, em maior grau de profundidade, a interpretação das particularidades dos comportamentos por atitudes dos indivíduos. (OLIVEIRA, 2002, p. 117).

Quanto aos objetivos, essa pesquisa pode ser classificada como exploratória, foi realizada na forma de levantamento bibliográfico, aplicação de questionários a profissionais da área e análise dos livros didáticos. Além disso, segundo Triviños (1987) "um estudo exploratório pode servir também para levantar possíveis problemas de pesquisa", como é o caso da educação patrimonial que ainda é pouco estudada, sobretudo, no tocante à Geografia.

Fizeram parte da pesquisa professoras de Geografia do Colégio Estadual Marechal Artur da Costa e Silva do município de Porto Nacional. A coleta de dados foi realizada no dia 24 de março de 2015 por meio de um questionário semiestruturado com seis perguntas abertas. Para a análise, os dados foram organizados, investigados e, em seguida, discutidos com base em leituras. Para garantir o anonimato foram utilizadas as abreviações P1 (professora 1) e P2 (professora 2).

\section{ANÁLISE dos LIVROS DIDÁticos}

Os livros didáticos devem ser uma ferramenta para auxiliar o professor em alguns conteúdos e não um guia a ser seguido do início ao fim. Baganha (2010) ressalta que os livros produzidos para os educadores no final do século XIX tinham como objetivo fornecer conteúdos que deveriam ser ensinados aos alunos e, ao mesmo tempo, servir de instrumento para aprender o método de ensino. Já no século XX, novas diretrizes e legislações de ensino, decorrentes das mudanças sociais, políticas e econômicas, foram determinantes na estrutura e concepção dos materiais didáticos, possibilitando aos educadores selecionar conteúdos e criar um método para transmiti-los ao educandos.

O livro didático é um instrumento importantíssimo e específico de ensino e aprendizagem formal na escola brasileira, tido como um dos principais recursos utilizados pelos educadores para a organização do conteúdo curricular e até mesmo para o exercício da atividade docente, no entanto, é importante destacar que não é o único material que educadores e educandos utilizarão durante o processo de ensino-aprendizagem. Dessa forma, os livros necessitam estar inclusos nas políticas educacionais por serem ferramentas políticas e ideológicas, veículos de disseminação de conhecimento e, ainda, fontes de informação e materiais de apoio e pesquisa para educando e educador (LAJOLO, 1996; LIBERALESSO, 2013).

Os livros didáticos foram efetivamente introduzidos nas escolas brasileiras por meio de um programa específico, o Programa Nacional do Livro Didático (PNLD), instituído pelo Decreto n ${ }^{\circ}$ 91.542/ 1985 (BRASIL, 1985), que tem o Ministério da Educação e Cultura (MEG) como órgão responsável pela organização, execução e aquisição desse material para toda a rede pública de ensino, cuja distribuição é gratuita (ZAMBOM; TERRAZZAN, 2012).

O livro didático é um material para ser utilizado em uma situação específica, ou seja, durante o processo de ensino-aprendizagem tanto em grupos como individualmente. Segundo Lajolo (1996) a decisão de fazer do livro didático um aliado ou inimigo parte do educador em relação às escolhas que faz no seu cotidiano escolar.

Diante disso, um dos objetivos dessa pesquisa foi fazer a análise de livros didáticos de Geografia, examinando-os diante de que seria possível encontrar, em seu conteúdo, a questão da pluralidade cultural, quer seja em textos ou imagens. Como o livro didático muitas vezes é, ou torna-se, o único instrumento de trabalho do professor, seja por vontade própria ou necessidade, é de suma importância analisá-los em busca de compreender se auxiliam ou não no processo educacional. Os livros que foram analisados são aqueles utilizados pelas professoras de Geografia do Colégio Estadual Marechal Artur da Costa e Silva, trata-se da coleção "Projeto Araribá" de 2010, que é uma coleção de livros disponibilizada pelo MEC a partir do PNLD, que tem como principal objetivo subsidiar o trabalho pedagógico dos professores.

\section{AnÁlise E Discussão DE RESUltados}

Foram realizadas entrevistas com duas professoras da disciplina de Geografia da escola pesquisada por meio de questionário semiestruturado com seis perguntas pré-estabelecidas, finalizando com uma análise 
das respostas. A professora identificada como P1 é contratada e leciona há três anos na escola, quanto a sua formação acadêmica possui graduação em licenciatura plena em Geografia pela Universidade de São Paulo (USP), em 2009 e é mestranda no curso de Pós-Graduação em Geografia pela Universidade Federal do Tocantins (UFT). A professora P2 também é contratada e leciona há um ano na escola, foi graduada em licenciatura plena em Geografia pela Universidade Federal do Tocantins em 2011.

Às professoras, perguntou-se qual sua compreensão por cultura. De acordo com elas:

P1: Cultura é o modo de vida de uma pessoa, uma comunidade, são os costumes, as tradições, o modo de agir de um determinado grupo. Levando pro lado artístico cultura são as mais variadas formas de se expressar artisticamente.

P2: Todos os costumes, crenças e saberes que formam a identidade de um indivíduo ou grupo social.

O processo histórico de socialização em que se aprende a fazer parte de um grupo social caracteriza a produção de um senso coletivo e constrói a identidade de cada sociedade, bem como de seus indivíduos. A cultura é a produção de fenômenos que contribuem, a partir da representação ou reelaboração simbólica das estruturas materiais, para compreender, reproduzir ou transformar o sistema social. Sua eminência dinâmica se transmite e se aprende, e é neste processo de socialização que aprendemos a formar parte do grupo ao qual estamos inseridos, adquirindo a nossa identidade (HORTA; GRUNBERG; MONTEIRO, 1999).

A cultura é constituída pelo conjunto dos saberes, fazeres, regras, normas, proibições, estratégias, crenças, idéias, valores, mitos, que se transmite de geração em geração, se reproduz em cada indivíduo, controla a existência da sociedade e mantém a complexidade psicológica e social. Não há sociedade humana, arcaica ou moderna, desprovida de cultura, mas cada cultura é singular. (MORIN, 2002, p. 56).

Quando perguntado às entrevistadas se desenvolvem atividades na escola voltadas à área cultural do município e por quais meios, as respostas foram unânimes:

P1: Sim, temos alguns projetos na escola como o "Café Literário" e saraus realizados bimestralmente.
P2: Sim, temos o projeto "Café Literário", realizamos sarau na escola e participamos com os alunos na Semana da Cultura aqui de Porto.

Evidencia-se que o patrimônio cultural de Porto Nacional há algum tempo vem sendo alvo de trabalhos desenvolvidos nas instituições de ensino, simbolizando e constituindo parte da história, representando e fazendo parte da memória e identidade social da cidade.

Ledur (2012) ressalta que uma sociedade organizada é a maior geradora de ações educativas de valorização do patrimônio cultural de uma região, ou seja, de todos os bens de natureza material e imaterial portadores da identidade dos diferentes grupos sociais. Essas ações devem ser instigadas em sala de aula por ser um importante instrumento educacional para o exercício da cidadania. Segundo Casco (2005, p. 2):

Elaborar projetos educativos voltados para a disseminação de valores culturais, formas e mecanismos de resgate, preservação e salvaguarda, assim como para a recriação e transmissão desse patrimônio às gerações futuras é, sobretudo, um projeto de formação de cidadãos livres, autônomos e sabedores de seus direitos e deveres.

Segundo Soares (2008, p. 8) "muito há o que se fazer em termos de educação para o patrimônio", pois, embora exista o reconhecimento da importância e da valorização do patrimônio histórico cultural, as atividades educativas nas escolas voltadas para esse fim que potencializam e estimulam a formação da cidadania apenas são encontradas em registros de experiências com a educação patrimonial no universo escolar, e geralmente são frutos de parceria entre o poder público local, universidades e o Iphan, pois ainda são poucos os estudos acadêmicos e livros didáticos que problematizam essa temática no país.

Atualmente, a palavra "patrimônio" pode vir acompanhada de outra para especificá-la e qualificá-la, como patrimônio cultural, patrimônio arquitetônico, patrimônio econômico etc. No caso específico deste trabalho, foi abordada a educação patrimonial aplicada ao ensino de Geografia, especificamente sobre o patrimônio histórico e cultural do município de Porto Nacional.

Desmitificar a ideia de que o patrimônio cultural é encontrado apenas nos museus deve ser a proposta da educação patrimonial voltada ao ensino de Geografia, levando os alunos a descobrirem a importância de valorizar o patrimônio cultural local, tomando conhecimento 
de sua história, bem como a implementação de politicas públicas de conservação desse patrimônio (LEDUR, 2012).

As professoras entrevistadas também ressaltaram a importância de valorizar e preservar o patrimônio do município de Porto Nacional. Observam-se os relatos:

\begin{abstract}
P1: Eu vejo o patrimônio cultural de Porto Nacional de suma importância para a valorização de nossos costumes, de nossa cultura. Sabemos que o patrimônio é a arquitetura da cidade com sua parte antiga e que, na verdade, nada mais é do arte pura, é de suma importância para as nossas futuras gerações que poderão presenciar através desse patrimônio a riqueza de nossa cultura.
\end{abstract}

P2: Ele ajuda a contar a história dos portuenses, através do seu conjunto histórico, de suas casas, de suas ruas, de seus monumentos, bem como a catedral.

Uma vez que o patrimônio histórico é um bem cultural, torna-se ponto de partida do processo de ensino-aprendizagem da Geografia, funcionando como facilitador para conhecer, usar, desfrutar e transformar os patrimônios culturais, ou seja, ao mesmo tempo em que está apropriando e valorizando, proporciona a formação da identidade e cidadania das comunidades às quais estão inseridos (ZANON; BRANCO; MAGALHÃES, 2009).

A preservação do patrimônio, uma vez despertada, deve ser empreendida de forma espontânea, não por obrigação ou Lei. Segundo Kanitz e Ribeiro (2014), iniciativas de educação patrimonial podem auxiliar o indivíduo a se identificar com o espaço e, mesmo que não o aprecie, reconheça sua importância e consiga respeitá-lo.

Ainda segundo essas autoras, o processo de tombamento consegue ressaltar a importância do patrimônio, cujo ato é muito significativo, juntamente com iniciativas de educação patrimonial, pois protege o patrimônio cultural dos grupos formadores da sociedade brasileira, por meio da captação do interesse tanto da comunidade local quanto de turistas para a preservação do espaço.

A cultura, quando discutida em sala de aula, ressalta a importância do patrimônio cultural, já que estão intrinsecamente interligadas, possibilitando a ampliação do entendimento de patrimônio e cultura, e favorecendo, com isso, o reconhecimento e inclusão das relações vividas e significadas pelos educandos a respeito dos bens culturais de seus contextos sociais (LEDUR, 2012).

A educação patrimonial trabalhada em sala de aula na disciplina de Geografia é de fundamental importância em todos os níveis do processo educativo, pois contribui para a formação e consolidação da cidadania na sociedade. Em vista disso, fez-se necessário conhecer e analisar metodologicamente o processo de construção deste saber científico no Colégio Marechal Artur da Costa e Silva a partir dos métodos e práticas pedagógicas utilizados pelas professoras de Geografia.

O que diz respeito à discussão sobre o patrimônio cultural, tanto em sala de aula quanto na escola, acarretou nas seguintes observações:

P1: Sim, já abordei a temática sim em sala de aula, e em uma outra escola fizemos uma aula campo na cidade de Natividade, e vejo como super importante se trabalhar em sala de aula sobre esses aspectos que são relevantes pra nossa história e nossa cultura. Mas, infelizmente isso é pouco visto e debatido em nossas escolas.

P2: Sim, já abordei essa temática em sala e, recentemente, levamos uma turma do $9^{\circ}$ ano para uma aula campo no centro histórico de Porto.

A educação patrimonial voltada ao ensino de Geografia não deve ser vista apenas como atividade pedagógica, pois ela é mais do que uma metodologia, portanto, não deve ser apenas uma disciplina a mais na prática educacional a ser acrescentada no currículo, mas um processo constante de ensino-aprendizagem que tem por objetivo central e foco de ações o patrimônio (SILVA, 2007).

Ao trabalhar a educação patrimonial entre as disciplinas obrigatórias no currículo escolar torna-se indispensável abordar os temas transversais que devem ser difundidos de maneira geral em todas as instituições escolares, propiciando um resultado coeso e enriquecedor, além de permitir a todo instante o desenvolvimento de tais ações dentro e fora da sala de aula (LEDUR, 2012).

A educação patrimonial não é um método educativo novo, portanto, deve atentar aos objetivos estabelecidos, aos pressupostos ou marcos teóricos que balizam a instituição e ao público-alvo da ação pedagógica. Desta forma, é fundamental que os vínculos de significação que uma comunidade estabelece ao longo de sua história sejam baseados nos momentos vividos, em que 
suas memórias se mesclam às memórias do distrito formando a base do que entendemos por identidade, para tanto, devem-se discutir os interesses sociais, políticos ou econômicos que velam por projetos desconectados da realidade e do seu papel transformador (ZANON; BRANCO; MAGALHÃES, 2009).

Embora os Parâmetros Curriculares Nacionais (PCN) preconizem as práticas de educação patrimonial, essas são trabalhadas de forma tímida, pois os livros didáticos trabalhados em sala de aula, geralmente, não abordam esse tema. Ledur (2012) ressalta que os professores devem trabalhar a história local em paralelo com o livro didático.

Quando perguntado às professoras se o livro didático utilizado em sala de aula aborda o patrimônio cultural, foi respondido que:

\section{P1: Não, infelizmente não.}

P2: Não, em alguns livros abordam sobre a diversidade cultural das regiões.

O livro didático utilizado em sala de aula deve promover a identidade cultural, a preservação de uma cultura e a valorização de um patrimônio, pois a melhor forma de preservar é através da educação patrimonial, formadora da identidade cultural de um indivíduo (SOARES, 2008).

Já em relação a eventos que tratam da questão do patrimônio cultural e sua abordagem em sala de aula, ambas evidenciaram que não há qualquer tipo de curso de capacitação para os professores:

\section{P1: Não, nunca.}

\section{P2: Não.}

A realização de eventos voltados para a formação do professor em relação à questão do patrimônio cultural e de como abordá-la em sala de aula parte da necessidade de um prévio reconhecimento dos espaços culturais locais, e da criação de um orgulho de pertencimento de um indivíduo a este local. A educação patrimonial, enquanto metodologia educativa, põe em discussão a apropriação do conhecimento patrimonial pelo educando para, consequentemente, proporcionar o reconhecimento da herança cultural e a formação de uma consciência histórica, já que sua valorização e preservação dependem desse conhecimento (HORTA; GRUNBERG; MONTEIRO, 1999).

\section{Análise da coleção Projeto Araribá}

O livro didático diferencia-se dos demais por se constituir como um importante recurso na escola, ferramenta útil no processo de ensino-aprendizagem tanto para educandos (como forma de organizar e sistematizar um assunto) quanto para os educadores (para reforçar seus conhecimentos sobre um assunto específico ou receber sugestões de como apresentá-lo em sala de aula). Ressalta-se ainda que o livro didático precisa ser mais voltado para a realidade do aluno, assim, considera-se fundamental analisar cuidadosamente as atividades propostas e as didáticas utilizadas na condução das mesmas para oferecer um ensino de qualidade (LIBÂNEO, 2002).

Sabe-se que o livro didático possui características como lógica, público específico e utilização restrita. Diante disso, analisou-se a coleção "Projeto Araribá" no intuito de conhecer como os livros didáticos de Geografia utilizados pelas professoras entrevistadas abordam a temática da diversidade e pluralidade cultural.

Figura 1. Coleção Projeto Araribá.
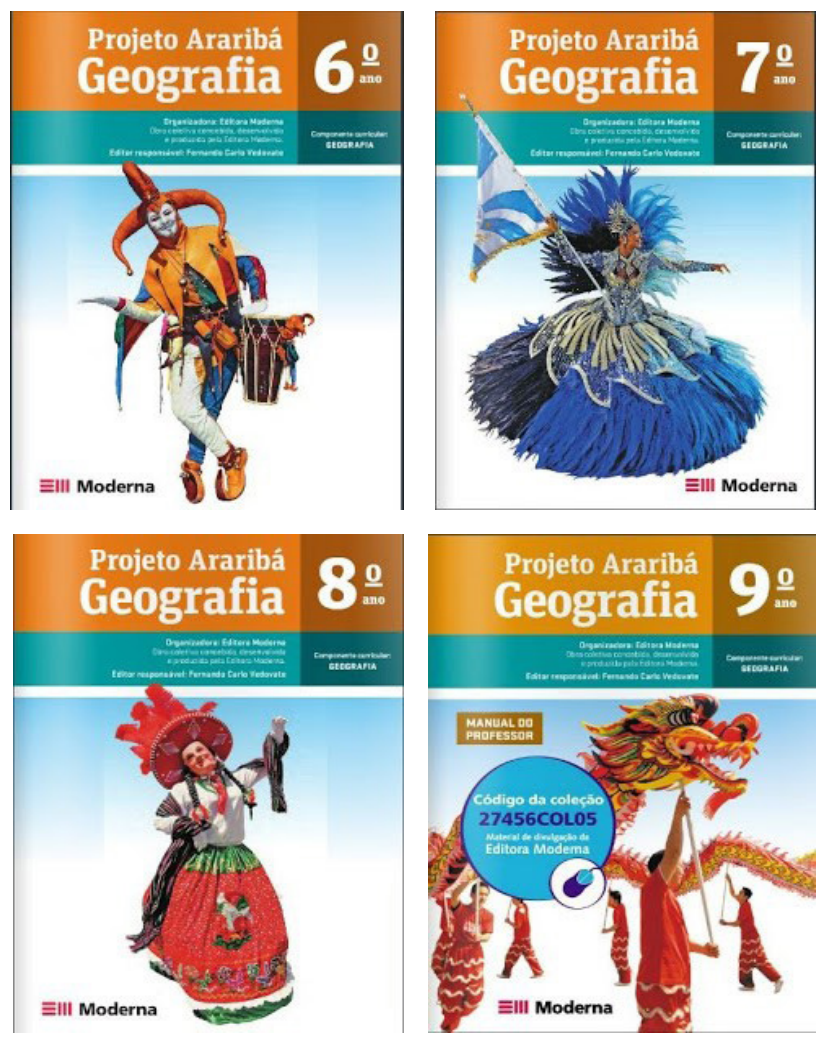

Fonte: Projeto Araribá Geografia (2015).

Os livros analisados compõem a coleção "Projeto Araribá" componente curricular: Geografia (Figura 1) destinados aos $6^{\circ}, 7^{\circ}, 8^{\circ}$ e $9^{\circ}$ anos do Ensino Fundamental, 
sendo compostos de quatro volumes estruturados em oito unidades (Tabela 1), subdivididas em quatro temas cada, além de boxes que trazem curiosidades e sugestões de filmes e livros, há as seções "Saiba mais" e "Compreender um texto" (complementação com textos e perguntas sobre assuntos abordados na unidade).

Tabela 1. Conteúdos proposto no livro didático Projeto Araribá.

\begin{tabular}{|c|c|c|c|c|c|}
\hline \multicolumn{6}{|c|}{ Conteúdos propostos por volume e série } \\
\hline \multirow{9}{*}{$\begin{array}{l}\text { Livro } \\
\text { didático: } \\
\text { Projeto } \\
\text { Araribá }\end{array}$} & Un. & $6^{\circ}$ ano & $7^{\circ}$ ano & $8^{\circ}$ ano & $9^{\circ}$ ano \\
\hline & $1^{\mathrm{a}}$ & $\begin{array}{l}\text { A geografia e a } \\
\text { compreensão do mundo; }\end{array}$ & O território brasileiro; & $\begin{array}{l}\text { Geografia e } \\
\text { regionalização do espaço; }\end{array}$ & $\begin{array}{l}\text { Países e conflitos } \\
\text { mundiais; }\end{array}$ \\
\hline & $2^{\mathrm{a}}$ & O planeta Terra; & A população brasileira; & A economia global; & $\begin{array}{l}\text { Globalização e } \\
\text { organizações mundiais; }\end{array}$ \\
\hline & $3^{\mathrm{a}}$ & $\begin{array}{l}\text { Os continentes, as ilhas } \\
\text { e os oceanos; }\end{array}$ & $\begin{array}{l}\text { Industrialização e } \\
\text { urbanização do Brasil }\end{array}$ & O continente americano; & O continente europeu; \\
\hline & $4^{\mathrm{a}}$ & Relevo e hidrografia; & Região Norte; & $\begin{array}{l}\text { A população e a } \\
\text { economia da América; }\end{array}$ & Leste Europeu e CEI; \\
\hline & $5^{\mathrm{a}}$ & Clima e vegetação; & Região Nordeste; & A América do Norte; & O continente asiático; \\
\hline & $6^{\mathrm{a}}$ & O campo e a cidade; & Região Sudeste; & $\begin{array}{l}\text { América Central, } \\
\text { América Andina e } \\
\text { Guianas; }\end{array}$ & $\begin{array}{l}\text { Ásia: destaques } \\
\text { regionais; }\end{array}$ \\
\hline & $7^{\mathrm{a}}$ & $\begin{array}{l}\text { Extrativismo e } \\
\text { agropecuária; }\end{array}$ & Região Sul; & América Platina; & O continente africano; \\
\hline & $8^{\mathrm{a}}$ & $\begin{array}{l}\text { Indústria, comércio e } \\
\text { prestacão de servicos. }\end{array}$ & Região Centro-Oeste. & O Brasil. & Oceania e regiões polares. \\
\hline
\end{tabular}

Fonte: Vedovate (2010), adaptada pela autora.

No primeiro livro analisado, que corresponde ao $6^{\circ}$ ano, observou-se na primeira unidade uma preocupação quanto ao entendimento dos educandos em relação à importância do estudo da Geografia, sendo tratados de forma superficial temas que dariam subsídios ao educador para trabalhar a pluralidade cultural que está presente no espaço geográfico, no lugar e também na paisagem. Nas demais unidades são abordados temas relevantes, no entanto, não há evidências significativas no que se refere à questão cultural ou patrimonial, tanto em textos quanto em imagens.

Com relação ao livro do $7^{\circ}$ ano, apesar da primeira unidade abordar a questão da diversidade cultural de forma superficial, o educador pode tomá-la como ponto inicial para trabalhar, estreitando esse assunto para o local de vivência do aluno. Na segunda unidade, a questão da pluralidade cultural é abordada, ressaltando a grande diversidade étnica de nosso país. Já a terceira unidade trabalha a questão urbana, no entanto, não é abordada culturalmente, mesmo sendo possível e muito enriquecedor, já que nos centros urbanos podem-se encontrar diferentes grupos sociais e culturais.
As unidades de quatro a oito abordam as regiões brasileiras, nelas encontram-se, mesmo escassos, conteúdos de significativa relevância voltados ao patrimônio histórico e cultural brasileiro, tratam de exercícios que remetem às atividades turísticas no estado do Piauí (Nordeste), existência de museus, casarões, igrejas e outros monumentos (Sudeste), as cataratas de Foz do Iguaçu, tombadas como patrimônio natural da humanidade, bem como as ruínas de São Miguel das Missões tombadas pela Unesco (Sul), catedral de Brasília e Pantanal (CentroOeste), onde a questão cultural foi atrelada à questão turística, o que ocorre comumente em outros livros, no entanto, nada remete à questão cultural da região Norte.

No livro analisado que corresponde ao $8^{\circ}$ ano, não foram encontradas imagens ou textos que tenham ligação com a pluralidade cultural da primeira a oitava unidades (exceto quarta e sexta), o que não dá subsídios ao professor para o trabalho com educação patrimonial. Já a quarta unidade menciona algo sobre a diversidade étnica, cultural e econômica da América, ilustrando características dos povos nativos e oriundos de outros continentes, além de um texto sobre a miscigenação do 
povo brasileiro. Na sexta unidade, apresentam-se imagens de patrimônios da humanidade como o Templo e Plaza Mayor (Guatemala) e as ruínas de Machu Picchu, no entanto, não são ressaltadas as suas descrições.

$\mathrm{Na}$ análise do livro trabalhado no $9^{\circ}$ ano, nas unidades primeira e segunda a questão da pluralidade cultural não foi observada tanto em elementos textuais quanto visuais. Já na terceira e quarta encontram-se imagens de paisagens de diferentes países do continente europeu que possuem algum significado cultural, favorecendo o trabalho dos docentes com a pluralidade cultural devido à rica diversidade do continente. Em relação às unidades quinta e sexta, há um breve texto que retrata a diversidade cultural e religiosa do continente asiático, com destaque às questões da religiosidade, bem como imagens de mesquitas, templos, palácios e festas que caracterizam algumas das religiões, apesar de algumas serem consideradas patrimônios culturais, isso não é especificado pelo livro.

Já a sétima unidade traz imagens de alguns aspectos naturais e culturais do continente africano, no entanto, não é evidenciada a questão cultural, mesmo sendo uma região rica nesse aspecto. A unidade oitava comenta sobre a minoria dos nativos da Oceania que lutam desde a colonização europeia pela preservação da cultura diante a desarticulação de seus costumes, línguas e valores, e traz ainda a questão multicultural e políticas restritivas aos imigrantes na Austrália.

Desta forma, pode-se observar que, no que se refere aos livros desta coleção, mesmo trazendo alguns comentários, textos, menções e imagens ilustrativas sobre a diversidade cultural, cultura e patrimônio, eles não dão suporte para o educador trabalhar de forma mais aprofundada e concreta a questão da pluralidade cultural em sala de aula por tratá-la de forma superficial, para tanto, o professor poderá utilizar os poucos textos e imagens que aparecem no decorrer da coleção para que a questão cultural e patrimonial seja introduzida, podendo ser incrementada com outras fontes ou atividades a serem desenvolvidas, bem como parcerias entre a escola e os órgãos de proteção ao patrimônio histórico e cultural local.

\section{CONSIDERAÇÕES FINAIS}

Os resultados apontam que as professoras entrevistadas compreendem o conceito de cultura e que atividades nesta área são desenvolvidas na escola por meio de projetos como "Café Literário", saraus e Semana da Cultura. A importância do patrimônio cultural de Porto Nacional também é evidenciada pelos entrevistados, pois ajuda a contar a história dos portuenses, bem como para a valorização dos costumes e da cultura local. A discussão sobre patrimônio cultural é preocupação tanto do colégio quanto das professoras entrevistadas, que ressaltam já terem abordado essa temática por meio de aula campo, entretanto, relatam que isso é pouco visto e debatido em suas escolas. Em relação aos livros didáticos utilizados, as entrevistadas relatam que eles não abordam a temática do patrimônio cultural. Relatam ainda que não participam de eventos que tratam essa questão e como abordá-la em sala de aula.

Diante disso, evidencia-se que, mesmo diante de amplas possibilidades de desenvolvimento da temática patrimonial pelo Ensino Fundamental, há carência do tema no livro didático, gerando diversas barreiras que não permitem ao educador desenvolver em seus educandos a capacidade de questionar, conscientizar e se posicionar diante de sua realidade local.

A educação patrimonial é uma medida eficaz para tirar tanto o educando quanto o educador da chamada "zona de conforto", pois, muitas vezes, o educando não está limitado a aprender com outras fontes, mas fica preso ao livro didático.

A cultura diz respeito a todas as práticas e instituições dedicadas à administração, renovação e reestruturação do sentido, institui as regras e normas que organizam a sociedade e os comportamentos individuais em todas as instâncias, inclusive na escola. A utilização da educação patrimonial na aprendizagem da disciplina de Geografia ganha relevância, principalmente por Porto Nacional ser tombado pelo Iphan como patrimônio histórico e cultural, possuindo importantes monumentos históricos como a Catedral Nossa Senhora das Mercês, Seminário São José, Caetanato, bem como o Museu Histórico e Cultural, a parte velha da cidade que conta com lindos casarões coloniais e importantes ruas como a do Cabaçaco e a da Cadeia. Essa riqueza cultural é de suma importância, uma vez que possibilita o diálogo entre a sociedade atual e a do passado, ao redor dos símbolos e das representações.

Desse modo, a educação patrimonial voltada ao ensino de Geografia tem o papel de desenvolver práticas pedagógicas que propiciem ao educando interpretar os bens culturais, tornando-os um elemento importante de promoção e vivência da cidadania, gerando com isso a responsabilidade na busca de valorizar e preservar o patrimônio cultural local, bem como promover 
o exercício da prática da cidadania participativa e a construção do conhecimento atrelado aos verdadeiros interesses populares.

Por existir uma relação de reciprocidade entre as interações produzidas pelo indivíduo e o surgimento da cultura com sua retroação sobre ele, a cultura baliza a vida em sociedade. Por meio de ações voltadas à reflexão, apropriação e preservação do patrimônio, podemos despertar nos educandos maior sensibilidade e consciência na construção de sua identidade e cidadania.

Ressalta-se, dessa forma, a necessidade da implantação de políticas públicas, principalmente com as escolas, com objetivo de desenvolver propostas de educação patrimonial com a comunidade local, de forma que possam fortalecer ou despertar a consciência da importância de conhecer e preservar todos os elementos que compõem seu universo cultural passado e presente, até mesmo para que possam compreender e participar ativamente da sua preservação, reconhecendo-se como seus cidadãos.

\section{REFERÊNCIAS}

BAGANHA, D. E. O papel e o uso do livro didático de ciências nos anos finais do Ensino Fundamental. 123p. Dissertação (Mestrado em Educação) - Universidade Federal do Paraná, Curitiba, 2010.

BRASIL. Decreto n ${ }^{\circ}$ 91.542, de 19 de agosto de 1985. Institui o Programa Nacional do Livro Didático, dispõe sobre sua execução e dá outras providências. Diário Oficial da União, Brasília, 20 ago. 1985. Seção 1, p. 12178.

CASCO, A. C. A. J. Sociedade e educação patrimonial. In: ENCONTRO NACIONAL DE EDUCAÇÃO PATRIMONIAL, 1., 2005, São Cristóvão. Anais... São Cristóvão: Iphan, 2005. Disponível em: <http:// bit.ly/2oP2hA4>. Acesso em: 19 abr. 2017.

HORTA, M. L. P.; GRUNBERG, E.; MONTEIRO, A. Q. Guia básico da educação patrimonial. Brasília: Iphan; Museu Imperial, 1999. Disponível em: < http:// bit.ly/2onlQfy>. Acesso em: 19 abr. 2017.

IBGE - INSTITUTO BRASILEIRO DE GEOGRAFIA E ESTATÍSTICA. Tocantins: Porto Nacional. 2015.
Disponível em: <http://bit.ly/2oVA5NY>. Acesso em: 20 abr. 2015.

IPHAN - INSTITUTO DO PATRIMÔNIO HISTÓRICO E ARTÍSTICO NAGIONAL. Ata da 59 Reunião do Gonselho Consultivo do Patrimônio Cultural. Rio de Janeiro, 2008. Disponível em: < http:// bit.ly/2oLE8vM>. Acesso em: 23 mar. 2015.

KANITZ, H. G.; RIBEIRO, F. M. S. N. Puxando pela memória: a casa grande simplício dias como ponto de compreensão entre as relações dos habitantes da cidade de Parnaíba/PI e seu patrimônio histórico. Turismo: Estudos \& Práticas, Mossoró, v. 3, p. 41 55, 2014. Número especial. Disponível em: <http://bit. ly/2ossYZJ>. Acesso em: 19 abr. 2017.

LAJOLO, M. Livro didático: um (quase) manual de usuário. Brasília: Em Aberto, 1996.

LEDUR, F. A. P. A educação patrimonial formal como elemento reconhecedor do patrimônio cultural em São Mateus do Sul-PR. Dissertação (Mestrado em Desenvolvimento Regional) - Universidade do Contestado, Canoinhas, 2012. Disponível em: <http://bit.ly/2oLXDV9>. Acesso em: 5 mar. 2015.

LIBÂNEO, J. G. Didática: velhos e novos temas. Goiânia: Edição do Autor, 2002.

LIBERALESSO, G. P. A educação patrimonial e o ensino de geografia: experiência nas escolas públicas da cidade de Santa Maria-RS. Dissertação (Mestrado em Geografia) - Universidade Federal de Santa Maria, Santa Maria, 2013. Disponível em: <http://bit.ly/2oPdRLq>. Acesso em: 5 fev. 2015.

MORIN, E. Os setes saberes necessários à educação do futuro. 6. ed. Brasília: Unesco, 2002.

NASGIMENTO, N. N.; BALSAN, R. O processo de patrimonialização no centro histórico de Porto Nacional - TO. Interface (Porto Nacional), Araguaína, n. 7, p. 61-74, 2014. Disponível em: <http://bit.ly/2pRQJv6>. Acesso em: 19 abr. 2017.

OLIVEIRA, R. F.; GARDOSO, L. R. Território, paisagem e lugar: o papel da Geografia na educação patrimonial e no ensino escolar. Revista Geográfica de 
América Central, San Pedro, v. 2, n. 47, p. 1-17, 2011. Disponível em: <http://bit.ly/2pCPfoJ>. Acesso em: 19 abr. 2017.

OLIVEIRA, S. L. Tratado de metodologia científica: projetos de pesquisas, TGI, TGC, monografias, dissertações e teses. São Paulo: Pioneira Thomson Learning, 2002.

PACHECO, I. A.; VARGAS, I. A. Educação patrimonial: um recurso para alfabetização cultural no Ensino Fundamental. Ateliê Geográfico, Goiânia, v. 3, n. 1, p. 82-96, abr. 2009.

PREFEITURA DE PORTO NACIONAL. Colégio Estadual Marechal Artur da Costa e Silva. 2015a. Disponível em: <http://bit.ly/2o4kBZ1>. Acesso em: 19 abr. 2014.

Um breve histórico sobre a fundação e emancipação política de Porto Nacional. $2015 \mathrm{~b}$. Disponível em: <http://bit.ly/2oVLltW>. Acesso em: 20 abr. 2014.

PROJETO ARARIBÁ GEOGRAFIA. São Paulo: Moderna, 2015.

REUNIÃO DO GONSELHO GONSULTIVO DO PATRIMÔNIO CULTURAL, 59., 2008, Rio de Janeiro.
Ata... Rio de Janeiro: Iphan, 2008. Disponível em: <http://bit.ly/2oLE8vM> Acesso em: 23 mar. 2015.

SILVA, K. C. G. Educação patrimonial: um convite à leitura do patrimônio cultural do município de Anápolis-GO. Dissertação (Mestrado em Gestão do Patrimônio Cultural) - Instituto de Pré-História, Universidade Católica de Goiás, Goiânia, 2007. Disponível em: <http://bit.ly/2oLTu3v>. Acesso em: 21 mar. 2015.

SOARES, A. L. R. (Org.). Educação patrimonial: teoria e prática. Santa Maria: UFSM, 2008.

VEDOVATE, F. G. (Org.). Projeto Araribá: geografia. 3. ed. São Paulo: Moderna, 2010. 4 v. $6^{\circ}$ ao $9^{\circ}$ ano.

ZAMBOM, L. B.; TERRAZAM, E. A. Estudo sobre o processo de escolha de livros didáticos organizado em escolas de educação básica. In: SEMINÁRIO DE PESQUISA EM EDUCAÇÃO DA REGIÃO SUL, 9., 2012. Anais... Caxias do Sul: UFRGS, 2012. Disponível em: <http://bit.ly/2oVVXZU>. Acesso: 16 mar. 2015.

ZANON, E. R.; BRANCO, P. M. C.; MAGALHÃES, L. H. (Orgs.). A construção de políticas patrimoniais: ações preservacionistas de Londrina, Região Norte do Paraná e Sul do país. Londrina: UniFil, 2009. 